\title{
Analysis of pharmacists' recommendations to address drug-related problems in chronic kidney disease patients as a basis to develop therapeutic drug monitoring form in an Indonesian hospital
}

\author{
Yusi Anggriani, Hesty Utami Ramadaniati, Enning Dhiah Pramularsih \\ Department of Clinical and Community Pharmacy, Faculty of Pharmacy, Pancasila University, Jakarta, Indonesia.
}

\begin{tabular}{|c|c|}
\hline CLE INFO & ABSTRACT \\
\hline & \multirow{11}{*}{$\begin{array}{l}\text { This study aimed to develop therapeutic drug monitoring (TDM) form based on analysis of pharmacists' } \\
\text { recommendation to address drug-related problems (DRPs) in chronic kidney disease (CKD) patients in a private } \\
\text { hospital. The profile of DRPs and pharmacists' recommendations, and clinical significance assessment of pharmacists' } \\
\text { recommendations before and after development of TDM form were compared. Focus group discussions (FGD) was } \\
\text { undertaken to evaluate the TDM form. There was similar pattern of DRPs identified using either pre-developed or } \\
\text { post-developed TDM form with dose selection being the most frequent DRP. No considerable difference regarding } \\
\text { physician acceptance rate to pharmacists' active recommendations before and after form development ( } 70.6 \% \text { and } \\
65.4 \% \text {, respectively). The commonest recommendations in both phases were dose change, drug discontinuation and } \\
\text { drug change. There was no statistical difference regarding the clinical significance of recommendations between both } \\
\text { phases but higher level of clinical significant recommendations was documented after form development. Major issues } \\
\text { of pre-developed form identified during FGD including unclear instruction of documentation, inadequacy to justify } \\
\text { the reasons for recommendations and non-integration within medical record. Development of TDM form unchanged } \\
\text { the profile of DRPs and pharmacists' recommendations, yet the developed form might generate more responses from } \\
\text { other health professions and clinically significant recommendations. }\end{array}$} \\
\hline $04 / 12 / 2017$ & \\
\hline & \\
\hline Avalraore omm & \\
\hline & \\
\hline & \\
\hline & \\
\hline & \\
\hline & \\
\hline & \\
\hline & \\
\hline
\end{tabular}

\section{INTRODUCTION}

Chronic kidney disease (CKD) is a major health problem worldwide. A meta-analysis revealed that global CKD prevalence was estimated between 11\%-13\% (Hill et al., 2016). CKD increases the risks of cardiovascular morbidity, mortality and decreases patients' quality of life (Gansevoort et al., 2013). World Health Organization (2013) reported that CKD accounted for approximately $1.5 \%$ of global death cases and nearly 30 million disability-adjusted life years lost. On global level, CKD contributed to considerable economic implication in healthcare systems (O'Callaghan et al., 2011; Ojo, 2014). CKD treatment expenditure in developed countries accounted for $2-3 \%$ of total

\footnotetext{
"Corresponding Author

Hesty Utami Ramadaniati; Faculty of Pharmacy, Pancasila University, Srengseng Sawah Jagakarsa, Jakarta Selatan, Indonesia 12640.

E-mail:h.ramadaniati@graduate.curtin.edu.au
}

healthcare expenditure although CKD patients represented less than $1 \%$ of the total population (Levey et al., 2007). Meanwhile, there were approximately 1.2 million CKD cases in Indonesia with the costs of treatment around US\$ 120 million (National Healthcare and Social Security Agent, 2016).

Drug therapies in the management of CKD are complex and specialized (Ibrahim et al., 2013). Consequently, CKD patients are prone to experiencing drug-related problems (DRPs) (Belaiche et al., 2012). The identification and resolution of DRPs have beneficial effects on disease management, patient's quality of life and healthcare cost (Ibrahim et al., 2013). Multiple measures should be implemented to ensure rational use of drug therapies including implementation of clinical pharmacy services (Society of Hospital Pharmacists of Australia Committee of Specialty Practice in Clinical Pharmacy, 2005). One of pharmacists' roles is to monitor drug therapy and give recommendations to address DRPs. Pharmacists' recommendations have been signified as one 
of parameters in evaluating the importance of clinical pharmacy services (Kim and Schepes, 2003; Kim et al., 2014; Abdel-Qader et al., 2010; Ramadaniati et al., 2014a). Further, an appropriate documentation system is required to demonstrate the nature of the services and justify the value of pharmacists' contribution within the healthcare system (Mc Lennan and Dooley, 2000; Davydov, 2003; Ramadaniati et al., 2014b).

Clinical pharmacy services have been implemented in some public and private hospitals in Indonesia. Nonetheless, little research has been undertaken to investigate the extent of clinical pharmacy services provided by those hospitals. In addition, the level of documentation of the services is variable and highly dependent on each hospital as there is no standardization established by Indonesian government. The study hospital has used therapeutic drug monitoring (TDM) form since 2014 to document clinical pharmacists' recommendation. To date, there is no evaluation to assess the effectiveness of the form to facilitate the documentation. Therefore, this study aimed to develop TDM form based on analysis of pharmacists' recommendation documentation to address DRPs in patients with CKD.

\section{MATERIAL AND METHODS}

This study was conducted in a Nephrology Ward of a 225-bed private hospital in Indonesia. This study used quantitative and qualitative approaches. Quantitative study was conducted to determine the profile and the clinical significance of pharmacist's recommendation before and after developing TDM form. Qualitative study was conducted using focus group discussion (FGD) to evaluate the previous TDM form and their suggestions to develop the form.

\section{Documentation of Pharmacists' Recommendations to Ad- dress DRPs using Pre-Developed and Post-Developed TDM Form}

TDM form consisted of sections including patient demographics, clinical status, medication profile, identified DRPs, recommendations and the physician acceptance of pharmacists' active recommendations. Pharmacists' active recommendations were defined as recommendations leading to changes in drug therapy. DRPs and pharmacists' recommendations were classified using Pharmaceutical Care Network Europe/PCNE Classification for DRPs v6.2 (Pharmaceutical Care Network Europe Foundation, 2010). Two phases of prospective observational study were conducted to determine the profiles of DRPs and pharmacists' recommendations

Phase 1

A six-month study was conducted using pre-developed TDM form. The principal researcher analyzed clinical pharmacists' documentation of DRPs and their recommendations.

Phase 2

During four-month study, the principal researcher analyzed the pharmacists' documentation using post-developed TDM form.

The principal researcher de-identified the documentation of the pharmacists' recommendations. The documentation was presented as vignettes describing the patients' clinical information,
DRPs and pharmacists' recommendations. Three independent panelists (clinical pharmacologist, nurse, clinical pharmacist) reviewed the cases independently and assessed the clinical significance of the recommendations. A meeting was organized between the panelists in order to reach consensus. For the clinical significance assessment, the rating system described by Dooley et al. (2003) was used. The profile of DRPs and pharmacists' recommendations, and clinical significance assessment of pharmacists' recommendations during Phase 1 and Phase 2 were compared. The study was approved by the study hospital human ethics committee.

\section{Focus Group Discussion (FGD)}

Eight clinical pharmacists in the study hospital were invited by principal researcher to be participants during FGD. A study information sheet and consent form were attached to the invitation. Independent facilitator facilitated the discussion and the principal researcher took notes during the discussion for crosschecking. The FGD was audio recorded and transcribed verbatim for thematic analysis. The new TDM form was developed in accordance to the suggestions.

\section{Data Analysis}

Demographic data, profiles of DRP and pharmacists' recommendations were summarized using descriptive statistics. The assessment of clinical significance of pharmacists' recommendations among the panelists prior to consensus was analyzed using KruskalWallis test. Kruskal-Wallis test was also conducted to compare the clinical significance of the recommendations after consensus during Phase 1 and Phase 2. Statistical analysis was conducted using SPSS version 22.0 (Chicago, IL., USA). Transcripts of FGD were coded and emergent themes were linked.

\section{RESULT AND DISCUSSION}

\section{Documentation of Pharmacists' Recommendations using Pre-Developed TDM Form}

Clinical pharmacists reviewed 96 CKD patients during Phase 1. Patients ranged from 33 to 96 years of age and there were slightly more male patients $(57.3 \%)$. The majority of patients (43.8\%) were diagnosed CKD stage 5 and nearly half of them had two comorbidities (mainly hypertension and diabetes mellitus).

Clinical pharmacists identified 35 DRPs (0.36 DRPs per patient) during data collection. DRP profiles with problems as primary domains are detailed in Figure 1. As seen in Figure 1 , domains of treatment effectiveness and adverse reactions constituted the majority of DRPs with similar proportion $(40.0 \%$ and $37.1 \%$, respectively). Analysis of DRP sub-domain uncovered that non-allergy adverse drug event was the most frequent DRP (n $=14,40.0 \%$ ).

Figure 2 describes DRP profiles with causes as primary domains. There were three major causes of DRPs: dose selection $(\mathrm{n}=12,34.3 \%)$, drug use process $(\mathrm{n}=10,28.6 \%)$ and drug selection $(\mathrm{n}=8,22.9 \%)$. Further analysis of sub-domain of DRP causes (see Figure 2) revealed five major causes of DRPs including inappropriate duplication, high dose, over-frequent dosage regimen, inappropriate timing of drug administration and failure to take/administer the drug. 




Fig. 1: Drug-related problems (DRPs) with Problems as Primary Domains identified during Phase $1(\mathrm{~N}=35)$.

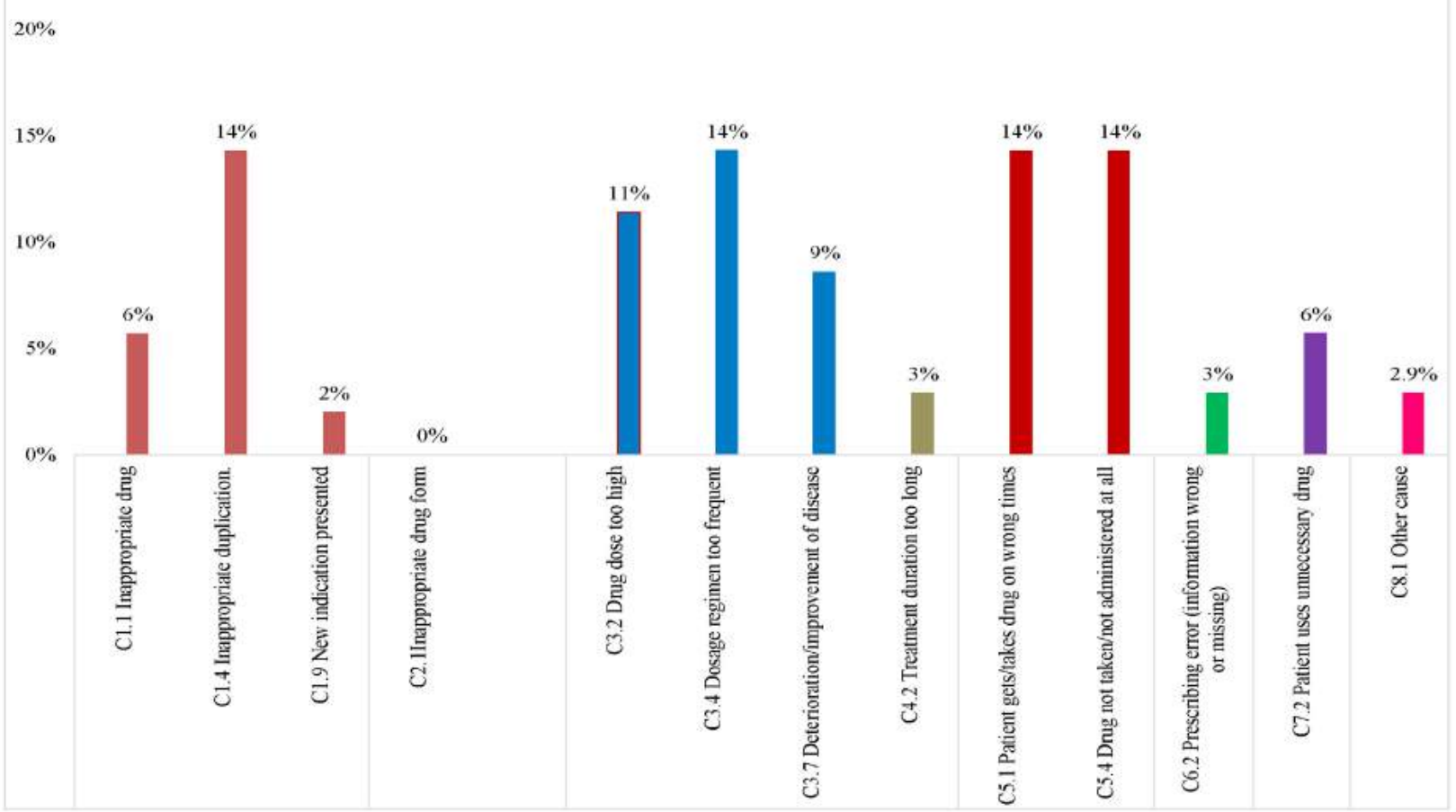

Fig. 2: Drug-related problems (DRPs) with Causes as Primary Domains identified during Phase $1(\mathrm{~N}=35)$.

There were 35 recommendations and more than twothirds of the recommendations were addressed to physicians with the remaining for nurses $(31.4 \%)$. Pharmacists' active recommendations constituted the majority of recommendations ( $\mathrm{n}=22 / 24,91.6 \%$ ) to physicians and approximately $70 \%$ of the recommendations was accepted by physicians. None of 
the recommendations for nurses was categorized as active recommendations as they were associated with provision of drug administration information. Breakdown of pharmacists' recommendations to physicians at drug level were as follows: drug cease $(n=9 / 24,37.5 \%)$, change of drug use instruction $(n=$ $7 / 24,29.2 \%)$, drug change $(n=4 / 24,16.7 \%)$, dosage change $(n=$ $2 / 24,8.3 \%)$ and drug addition $(\mathrm{n}=2 / 24,8.3 \%)$.

Figure 3 outlines the clinical significance assessment of pharmacists' recommendation by panelists. Overall there were significantly different ratings amongst the panelists $(p=0.01)$. The breakdown of the assessment revealed that there were similarities in the ratings $(\mathrm{p}=0.360)$ by Reviewer 2 (nurse) and Reviewer 3 (pharmacist), whilst Reviewer 1 (physician) demonstrated disparate rating $(\mathrm{p}<0.001)$. Reviewer 1 considered almost half of the recommendations were major in significance. By contrast, both Reviewer 2 and Reviewer 3 perceived that non-significant recommendations constituted the most frequent rating amounting more than $30 \%$. Further, consensus of panel revealed that nearly half of the recommendations were not clinically significant.

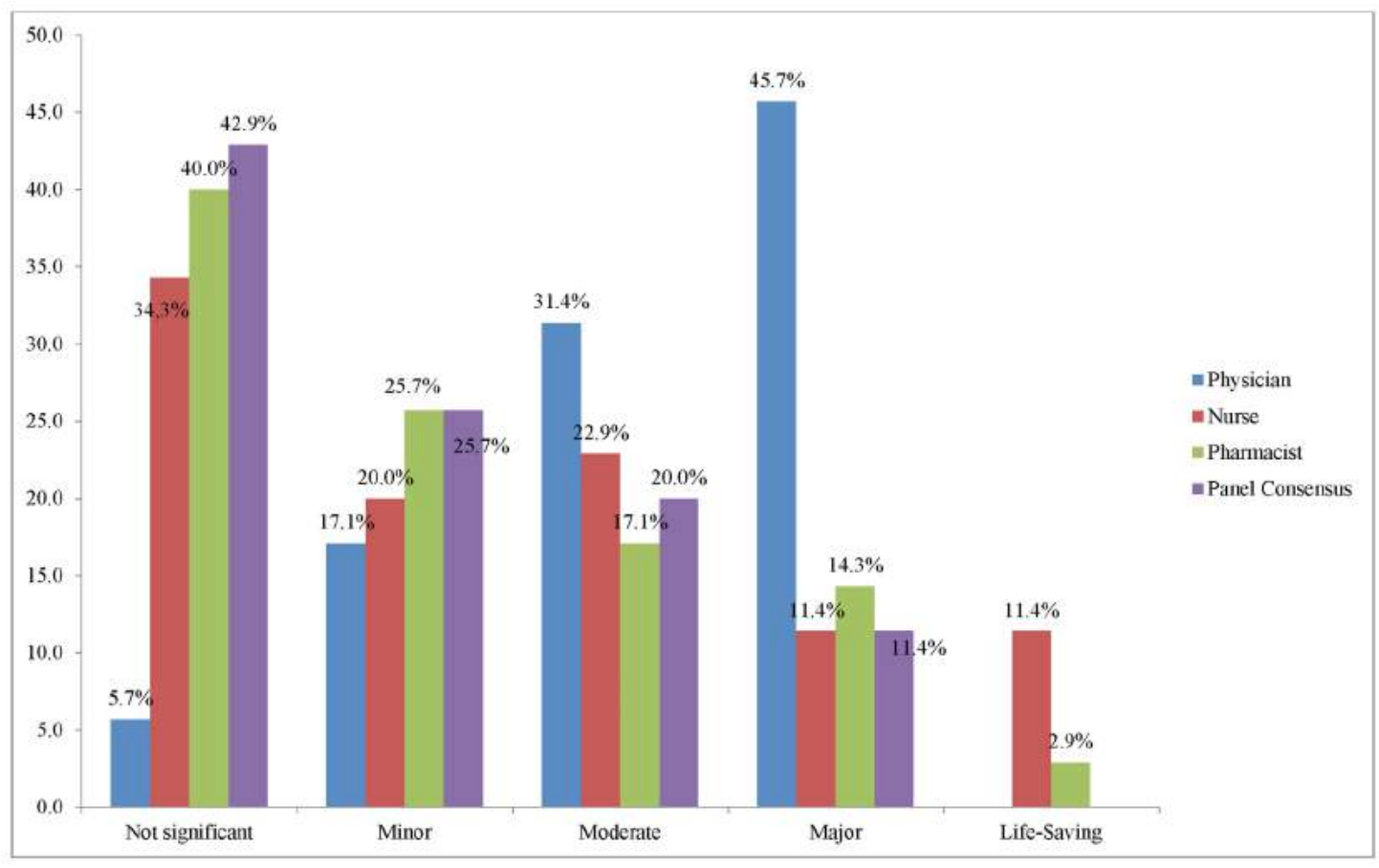

Fig. 3: Panel Assessment of Clinical Significance of Pharmacists' Recommendations during Phase $1(\mathrm{~N}=35)$.

\section{Issues associated with Recommendation Documentation using Pre-Developed TDM Form and Development of TDM Form}

The pharmacists participating in the FGD identified three main issues of documentation using pre-developed TDM form. The first issue was unclear instruction to fill out the form particularly when selecting DRP sub-domains. Secondly, no section was provided to include the relevant patients' clinical data to justify DRPs and pharmacists' recommendations. The last issue was non-integration of TDM form in patients' medical record within hospital information system. The quotes below exemplified the aforementioned issues:

"Some pharmacists have their own perceptions as to the way to fill out the form ... how to pick the DRP sub-domains." PA1

"It is essential to provide Subjective and Objective sections. We gave our reasons for recommendations. " PA2

"... I don't know where it is possible to put the TDM Form in the system. I mean the doctors and nurses would be aware when they [doctors and nurses] log in." PA3

After considering the issues that emerged during FGD, the clinical pharmacists developed and finalized the new form. There were two main features of the post-developed TDM form which were different from the previous form. The first feature was the inclusion of TDM form as the part of patients' medical record. This improvement was beneficial as the other healthcare professions (i.e. physicians and nurses) can read and subsequently respond to pharmacists' recommendations. Previously, the pharmacists should confirm their recommendations either through direct meeting or via phone call. After using the post-developed form, the pharmacists occasionally contacted physicians/nurses directly to seek their responses on DRPs that need immediate responses.

The second feature was the addition of "Subjective" and "Objective" sections to justify pharmacists' recommendations. The inclusion of these new sections encouraged the pharmacists to do ward round to gather the updated patients' data and to monitor the outcome of their recommendations.

\section{Documentation of Pharmacists' Recommendations using Post-Developed TDM Form}

There were 32 patients reviewed by clinical pharmacists during Phase 2. On average patients aged 65 years and male patients predominated (62.5\%). Majority of the patients $(68.8 \%)$ had been diagnosed with CKD stage 4 and stage 5 . 
Clinical pharmacists identified 33 DRPs (1.03 DRPs/ patient) during Phase 2 despite Phase 2 duration was shorter than Phase 1.

Figure 4 describes DRP profiles with problems as primary domains. Domains of treatment effectiveness, adverse reactions and treatment cost accounted for major DRPs with similar proportion $(36.4 \%, 33.3 \%, 27.3 \%$, respectively). This finding shows that on overall there was no considerable difference when comparing DRP profiles with problems as primary domains during Phase 1 and Phase 2.

Figure 5 describes DRP profiles with causes as primary domains. There were two major causes of DRPs: dose selection ( $\mathrm{n}$ $=14,42.4 \%)$ and drug selection $(\mathrm{n}=11,33.3 \%)$. The DRP pattern captured using post-developed TDM form was quite similar with that of pre-developed form (see Figure 2).

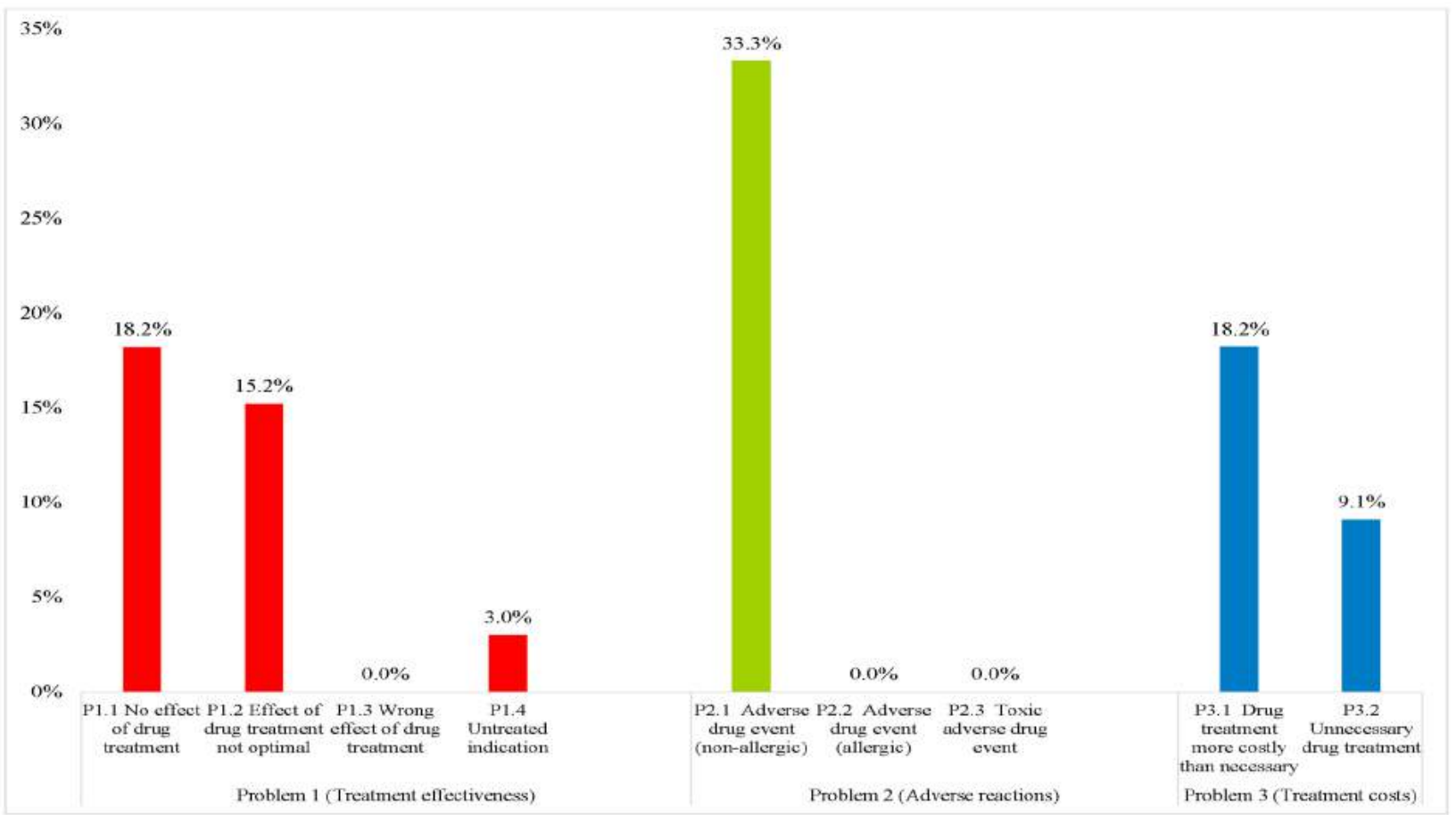

Fig. 4: Drug-related problems (DRPs) with Problems as Primary Domains identified during Phase $2(\mathrm{~N}=33)$.



Fig. 5: Drug-related problems (DRPs) with Causes as Primary Domains identified during Phase $2(\mathrm{~N}=33)$. 
During Phase 2, pharmacists gave 32 recommendations to resolve DRPs. The majority of the recommendations $(n=26 / 32$, $81.2 \%$ ) were given to physicians with less than $20 \%$ addressed to nurses. All recommendations to physicians were active recommendations, whilst no active recommendations were given to nurses. Breakdown of active recommendations to physicians at drug level included dosage change $(n=9 / 26,34.6 \%)$, drug cease $(\mathrm{n}=7 / 26,26.9 \%)$, drug change $(\mathrm{n}=6 / 26,23.1 \%)$, drug addition $(\mathrm{n}=2 / 26,7.6 \%)$ and change of drug use instruction $(\mathrm{n}=2 / 26$, $7.6 \%$ ). The type of recommendations during Phase 2 was not comparable with that of Phase 1 . The acceptance rate of active recommendations during Phase 2 was slightly lower (65.4\%) compared to that of Phase $1(70.6 \%)$.

Figure 6 details the clinical significance assessment of pharmacists' recommendation by panelists. There was similar pattern $(p=0.496)$ where all panelists assessed the majority of the recommendations in the range of minor-moderate in significance. Approximately $20 \%$ of the recommendations were considered as not significant according to physician and pharmacist, whilst nurse thought higher proportion $(27.3 \%)$. The similar rating was seen after the consensus.

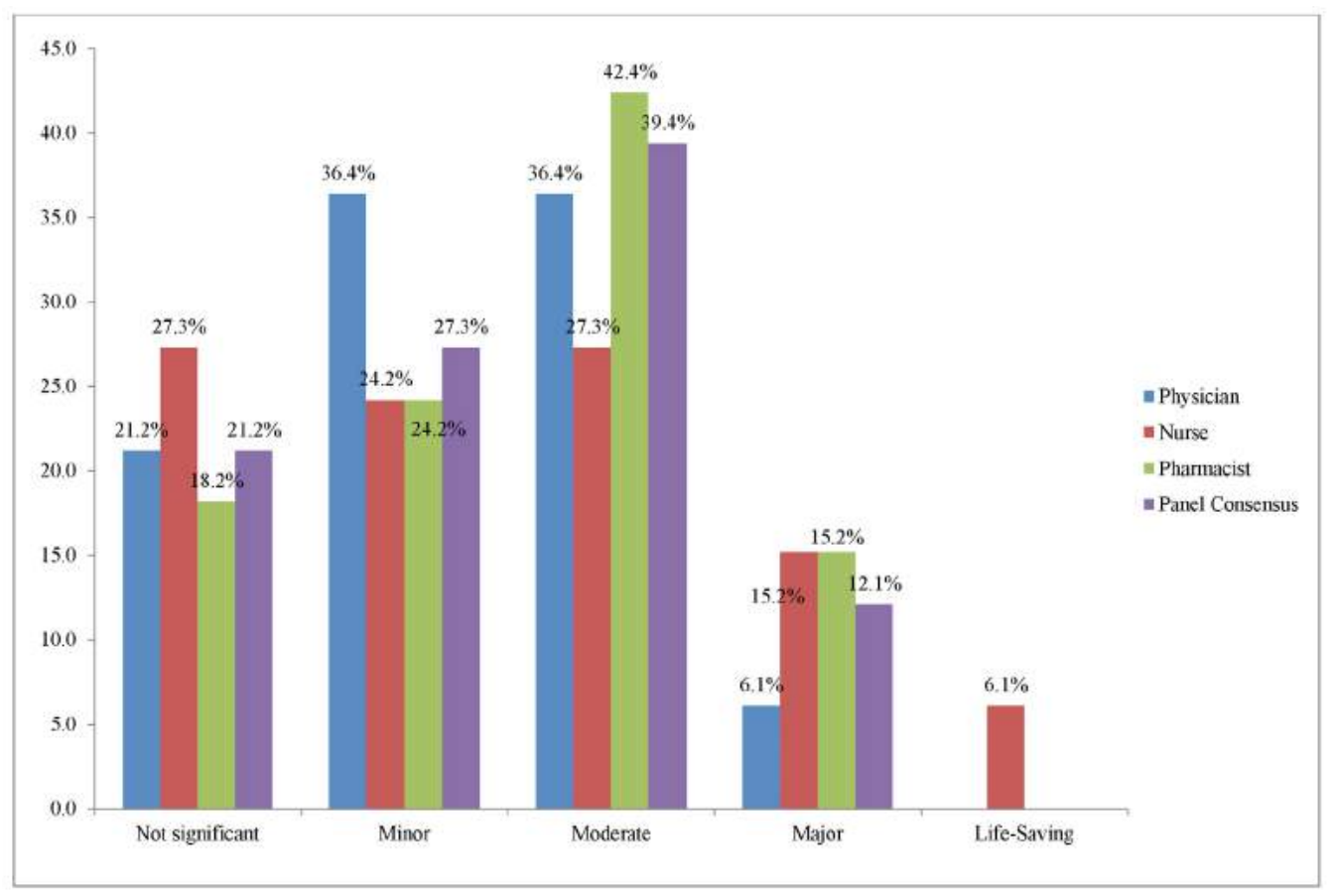

Fig. 6: Panel Assessment of Clinical Significance of Pharmacists' Recommendations during Phase $2(\mathrm{~N}=33)$.

When comparing the clinical significance of pharmacists' recommendations, there was no statistically difference $(p=$ 0.101 ) between both phases. However, when the rating of clinical significance was collapsed into significant (minor, moderate, major, life-saving) and not significant, the proportion of significant recommendation during Phase 2 was higher (81.2\%) compared with that of Phase 1 (58.9\%).

To the best of our knowledge, this is the first study in Indonesia evaluating the effectiveness of TDM form as the tool for pharmacists to identify DRPs and document their recommendations to resolve DRPs in CKD patients. The practice of pharmacy in hospital settings has transformed considerably and the documentation of pharmacists' recommendations has become increasingly important (Pugh, 1992). It can be understood that regulatory bodies in many countries have recommended that pharmacists record their recommendations and this activity is even mandatory in some countries (Society of Hospital Pharmacists of Australia Committee of Specialty Practice in Clinical Pharmacy, 2005; Millar, 2008; American Society of Health-System Pharmacists, 2003; Royal Pharmaceutical Society of Great Britain, 2005).
Numerous studies have pointed out that the documentation of pharmacists' recommendations can provide a great deal of information for assessing task workload and justifying staffing levels (Dooley et al., 2003; De Rijdt et al., 2008; Condren et al., 2004; Bosma et al., 2007). In addition, analysis of the recommendations involving DRPs from time to time can identify the trends of the problems during healthcare process. These trends can be monitored to evaluate the appropriateness of the solutions to correct the perceived problems (Davydov, 2003; Dodd, 2003).

In Indonesian context, Ministry of Health has recommended pharmacists to document their recommendations. This institution has published the standard of pharmaceutical care and sample of TDM form to assist pharmacists when documenting their recommendations (Directorate General of Pharmacy and Medical Devices, 2006). Nevertheless, a qualitative study to analyze pharmacy practice in some major hospitals in Indonesia revealed that appropriate documentation of pharmacists' recommendation was limited (Herman et al., 2013). Moreover, little study has been done in Indonesia to review the effectiveness of the TDM form. Our study uncovered three main issues of documentation form namely unclear instruction for using the 
form, unavailability of "Subjective" and "Objective" sections and lack of integration within patients' medical record.

In regard the guidelines for recommendation documentation, there is no clear instruction established in Indonesia particularly related to the extent and type of information to be documented and the standard format. Consistent with our finding, this issue has been highlighted in some studies (Millar, 2008; Pederson et al., 2000; Tenni and Hughes, 1996). This uncertainty may lead to confusion among the pharmacists. Therefore, the availability of guidelines for documenting the information on the TDM form established by pharmacy department at each institution might resolve this problem (Canadian Society of Hospital Pharmacists, 1999). The guidelines should be well-informed by conducting training for pharmacists prior to the implementation (American Society of Health-System Pharmacists, 2003).

Lack of "Subjective" and "Objective" sections was regarded as the shortcoming of the pre-developed TDM Form in the current study. The FGD participants in this study thought that the two sections were crucial to justify their assessment and likely to be more acceptable by other care providers. It has been substantiated that the detailed of pharmacists' recommendations along with the supporting reasons become some of indicators of quality patient care (Currie et al., 2003).

As with our finding, the American Society of HealthSystem Pharmacists (2003) has raised the issue with the importance of integration of the recommendation documentation. Documentation that is not a part of patients' medical record may not be able to provide timely information to other healthcare professional and likely to disrupt the continuity of patient care during transfer or discharge process. The integrated documentation would reveal the expertise and the responsibility of pharmacists (Currie et al., 2003). In addition, it is frequently that pharmacists convey their recommendations via oral communication to obtain immediate responses. In this case, the pharmacists still need to document their recommendations immediately after the situation has settled to ensure seamless communication with other care providers (American Society of Health-System Pharmacists, 2003).

In relation to the rate of DRP during Phase 1 and Phase 2 , the pharmacists were able to identify more DRPs when using post-developed form (1.03 DRPs/patient) compared to that of predeveloped form (0.36 DRPs/patient). The provision of "Subjective" and "Objective" section on the new form was likely to encourage the pharmacists to justify the reasons for their assessment leading to higher rate of DRP identification after the implementation of the new form. When comparing the rate of DRPs, other studies involving CKD patients either inpatient or ambulatory setting reported higher rate which ranged between 1.4-5.0 DRPs per patient (Ramadaniati et al., 2016; Possidente et al., 1999; Lim et al., 2003; Patel et al., 2005; Grabe et al., 1997; Mirkov, 2009; Pal et al., 2009). The differences of the rates may be attributable to complexity of the patients' medication regimens, the competency of the pharmacists and the type of study. Further, other studies uncovered incorrect dosing as the most common reported DRP which was consistent with our finding (Ramadaniati et al., 2016; Lim et al., 2003; Patel et al., 2005; Pal et al., 2009; Salgado et al., 2012; Stemer et al., 2012). With regards to clinical significance of pharmacists' recommendations, the majority were rated as clinically significant with higher proportion documented after the form development $(81.2 \%)$ as opposed to the pre-developed one $(58.9 \%)$. Other studies involving CKD patients had similar findings with this present study, particularly in relation to the result of Phase 2, signifying the positive impact of the recommendations on patient care (Possidente et al., 1999; Lim et al., 2003; Grabe et al., 1997).

Although our findings are promising, this study has some limitations. Due to small cohort of patients from a single institution, some results of this study may prevent extrapolation to the general population of CKD patients. Additionally, FGD was chosen as the method to identify barriers and improvements regarding recommendation documentation. Even with skilled facilitation, this method may not adequately extract dissenting opinions from participants. Nonetheless, this method was deemed suitable for the small group of participants to collect qualitative data on this topic of interest (Berg, 2004; Creswell, 2005).

\section{CONCLUSION}

Development of TDM form did not change the profile of DRPs and pharmacists' recommendations. However, the developed form was likely to generate more responses from other health professions due to its integration in the medical record and more pharmacists' recommendations with significant impact on patient care.

\section{CONFLICTS OF INTEREST}

Authors declare there are no conflicts of interest.

\section{SOURCE OF FUNDING}

Internal Research Scheme funded by Faculty of Pharmacy Pancasila University, South Jakarta, Indonesia.

\section{REFERENCES}

Abdel-Qader DH, Harper L, Cantrill JA, Tully MP. Pharmacists' interventions in prescribing errors at hospital discharge. Drug Saf, 2010; 33:1027-1044.

American Society of Health-System Pharmacists. ASHP guidelines on documenting pharmaceutical care in patient medical records. Am J Health-Syst Pharm, 2003; 60:705-707.

Belaiche S, Romanet T, Allenet B, Calop J, Zaoui P. Identification of drug-related problems in ambulatory chronic kidney disease patients: A 6-month prospective study. J Nephrol, 2012; 25:782-788.

Berg BL.2004. Focus group interviewing: Qualitative research methods for the social sciences. Boston: Allyn and Bacon.

Bosma L, Jansman FGA, Franken AM, Harting JW. Evaluation of pharmacist clinical interventions in a Dutch hospital setting. Pharm World Sci, 2007; 30:31-38.

Canadian Society of Hospital Pharmacists. 1996. Pharmaceutical care: information paper on the documentation of pharmaceutical care in the patient's health record. Ottawa: Canadian Society of Hospital Pharmacists.

Condren ME, Haase MR, Luedtke SA, Gaylor AS. Clinical activities of an academic pediatric pharmacy team. Ann Pharmacother, 2004; 38:574-578.

Creswell JW. 2005. Educational research: planning, conducting, and evaluating quantitative and qualitative research. Upper Saddle River Pearson Education.

Currie JD, Doucette WR, Kuhle J. Identification of the essential elements in the documentation of pharmacist-provided care. J Am Pharm Assoc, 2003; 43:41-49. 
Davydov L, Caliendo GC, Smith LG, Mehl B. Analysis of clinical intervention documentation by dispensing pharmacists in a teaching hospital. Hosp Pharm, 2003; 38:346-350.

De Rijdt T, Willems L, Simoens S. Economic effects of clinical pharmacy interventions: a literature review. Am J Health-Syst Pharm, 2008; 65:1161-1172.

Directorate General of Pharmacy and Medical Devices. 2006. Standard of Pharmaceutical Care in Hospital Setting. Jakarta: Indonesian Ministry of Health.

Dodd C. Assessing pharmacy interventions at Salisbury health care NHS trust. Hosp Pharm, 2003; 10:451-456.

Dooley MJ, Allen KM, Doecke CJ, Galbraith KJ, Taylor GR, Bright $\mathrm{J}$, et al. A prospective multicentre study of pharmacist initiated changes to drug therapy and patient management in acute care government funded hospital. Br J Clin Pharmacol, 2003; 57:513-521.

Gansevoort RT, Correa-Rotter R, Hemmelgarn BR, Jafar TH, Heerspink HJ, Mann JF. Chronic kidney disease and cardiovascular risk: epidemiology, mechanisms and prevention. Lancet, 2013; 382:339-352.

Grabe DW, Low CL, Baille GR, Eisele G. Evaluation of drugrelated problems in an outpatient hemodialysis unit and the impact of a clinical pharmacist. Clin Nephrol, 1997; 47:117-121.

Herman MJ, Handayani RS, Siahaan SA. Analysis of pharmacy practice by pharmacist in hospital setting. Jurnal Kesehatan Masyarakat Nasional, 2013; 7:365-372.

Hill NR, Fatoba ST, Oke JL, Hirst JA, O'Callaghan CA, Lasserson DS. Global prevalence of chronic kidney disease - A systematic review and meta-analysis. PLoS ONE, 2016; 11:e0158765.

Ibrahim N, Wong IC, Patey S, Tomlin S, Sinha MD, Jani Y. Drug related problem in children with chronic kidney disease. Pediatr Nephrol, 2013; 28:25-31.

Kim JM, Park SJ, Sohn YM, Lee YM, Gwak HS, Lee BK. Development of clinical pharmacy services for intensive care units in Korea. Springer Plus, 2014; 3:34-39.

Kim Y, Schepers G. Pharmacist intervention documentation in US health care system. Hosp Pharm, 2003; 12:1141114-7.

Levey AS, Atkins R, Coresh J. Chronic kidney disease as a global public health problem: approaches and initiatives-a position statement from Kidney Disease Improving Global Outcomes. Kidney Int, 2007; 72:247259.

Lim SB, Lim GK, Khog AL, Sivaraman P. Evaluation of the clinical and economic impact through a focused drug therapy review program in in-flight patients with renal impairment. ASHP Midyear Clinical Meeting 2003. p. 373.

McLennan DN, Dooley MJ. National survey of clinical activity documentation practices. Aust J Hosp Pharm, 2000; 30:6-9.

Millar T, Sandilya R, Tordoff J, Ferguson R. Documenting pharmacist's clinical interventions in New Zealand hospitals. Pharm World Sci, 2008; 30:99-106.

Mirkov S. Implementation of a pharmacist medication review clinic for haemodialysis patients. N Z Med J, 2009; 122:25-37.

National Healthcare and Social Security Agency (Badan Penyelenggara Jaminan Sosial). 2016. Biaya klaim BPJS. Jakarta: Badan Penyelenggara Jaminan Sosial.

O'Callaghan CA, Shine B, Lasserson DS. Chronic kidney disease: a large-scale population-based study of the effects of introducing the CKD-EPI formula for eGFR reporting. BMJ Open, 2011;1:e000308.
Ojo A. Addressing the global burden of chronic kidney disease through clinical and translational reserach. Transac Am Clin Clim Assoc, 2014; 125:229-246.

Pal AB, Boyd A, Depczynsky J, Chavez IM, Khan N, Manley $\mathrm{H}$. Reduced drug use and hospitalization rates in patients undergoing hemodialysis who received pharmaceutical care: A 2-year randomized controlled study. Pharmacotherapy, 2009; 29:1433-1440.

Patel HR, Pruchnicki MC, Hall LE. Assessment of chronic kidney disease service in high-risk patients at community health clinic. Ann Pharmacother, 2005; 39:22-27.

Pederson CA, Schneider PJ, Santell JP, Kelly EJ. ASHP national survey of pharmacy practice in acute care settings: monitoring, patient education, and wellness. Am J Health-Syst Pharm, 2000; 57:2171-2187.

Pharmaceutical Care Network Europe Foundation. 2010. Classification for drug related problems V6.2. Zuidlaren: Pharmaceutical Care Network Europe Foundation.

Possidente CJ, Bailie GR, Hood V. Disruptions in drug therapy in long-term dialysis patients who require hospitalization. Am J Health Syst Pharm, 1999; 56:1961-1964.

Pugh CB. Documenting the clinical interventions of pharmacists. Top Hosp Pharm Manage, 1992; 11:30-43.

Ramadaniati HU, Anggriani Y, Wowor VM, Rianti A. Drugrelated problems in chronic kidney disease patients in an Indonesian hospital: do the problems really matter? Int J Pharm Pharm Sci, 2016; 8:1-5.

Ramadaniati HU, Lee YP, Hughes JD. The difference in pharmacists' interventions across the diverse settings in a children's hospital. PLOS ONE, 2014a; 9(10):e110168.

Ramadaniati HU, Lee YP, Hughes JD. Snapshot versus continuous documentation of pharmacists' interventions: are snaphots worthwhile? J Pharm Pract Res, 2014b;44:205-212.

Royal Pharmaceutical Society of Great Britain. Guidance on recording interventions. Pharm J, 2006; 276:517-518.

Salgado TM, Moles R, Benrimoj SI, Fernandez-Llimos F. Pharmacist' interventions in the management of patients with chronic kidney disease: a systematic review. Nephrol Dial Transplant, 2012; 27:276-292.

Society of Hospital Pharmacists of Australia (SHPA) Committee of Specialty Practice in Clinical Pharmacy. SHPA standards of practice for clinical pharmacy. J Pharm Pract Res, 2005; 35:122-146.

Stemer G, Laml-Wallner G, Kuegler I, Poelzleitner P, Messner $\mathrm{S}$, Steininger S. Comprehensive evaluation of clinical pharmacists' interventions in a large Austrian tertiary care hospital. Eur J Hosp Pharm, 2012:10.1136.

Tenni PC, Hughes JD. National survey of clinical pharmacy services. Aust J Hosp Pharm, 1996; 26:416-427.

World Health Organization. 2013. Global Health Estimates Summary tables: Death by Cause, Age and Sex. Geneva: World Health Organization.

\section{How to cite this article:}

Anggriani Y, Ramadaniati HU, Pramularsih ED. Analysis of pharmacists' recommendations to address drug-related problems in chronic kidney disease patients as a basis to develop therapeutic drug monitoring form in an Indonesian hospital. J App Pharm Sci, 2018; 8(02): 071-078. 